\title{
Microhardness and Fracture Toughness of Dental Materials by Indentation Method
}

\author{
Aylin Şakar-Deliormanli ${ }^{1}$ and Mustafa Güden ${ }^{1,2}$ \\ ${ }^{1}$ Materials Science and Engineering Program, Izmir Institute of Technology, Urla, Izmir, Turkey \\ ${ }^{2}$ Mechanical Engineering Department, Izmir Institute of Technology, Urla, Izmir, Turkey
}

Received 17 February 2004; revised 11 April 2005; accepted 13 April 2005

Published online 6 October 2005 in Wiley InterScience (www.interscience.wiley.com). DOI: 10.1002/jbm.b.30371

\begin{abstract}
The main objective of this study was to measure the fracture toughness of the human teeth enamel using the microindentation technique and to compare the results calculated from the equations developed for Palmqvist and radial-median cracks. Vickers microhardness measurements of dental ceramic (alumina) and human teeth were performed using indentation fracture method. The fracture toughness of enamel was calculated using different equations reported in the literature. Vickers microhardness of the sintered alumina specimen (98.8\% theoretical density) was measured to be $14.92 \mathrm{GPa}$ under $\mathbf{9 . 8 \mathrm { N }}$ indentation load. Three equations based on the radial-median cracks were found to be applicable for the fracture toughness determination of the enamel. Results show that indentation fracture method is adequate to measure microhardness and fracture toughness of dental materials. However the calculation of fracture toughness depended on the nature of the cracks and also on the location of the indentation. Therefore, it is necessary to identify the crack profile and to select the appropriate equation for accurate fracture toughness values. (C) 2005 Wiley Periodicals, Inc. J Biomed Mater Res Part B: Appl Biomater 76B: 257-264, 2006
\end{abstract}

Keywords: alumina; ceramic; fracture toughness; microdamage; dental/craniofacial material

\section{INTRODUCTION}

Much research effort has been directed for improving the strength and fracture toughness of dental materials and increasing their current and potential utilization in structural applications. Understanding the mechanical properties of human teeth is an important research area, not only for the clinical tooth preparation but also for the development of tooth like restorative materials. ${ }^{1}$ Although resistance to fracture is an important mechanical property for teeth, there exist inconsistencies when the toughness values of a given material are considered as there are many techniques available for the measurement of the fracture toughness, hardness, and related properties.

Different techniques and specimen geometries are currently used to determine toughness and hardness. One group of techniques comprise conventional fracture mechanics using notches and secondarily induced precracks including single edge notched bend testing, ${ }^{2}$ chevron V-notched bar or short rod testing, ${ }^{3,4}$ and the bridge compression test. ${ }^{5}$ While,

Correspondence to: A. Şakar-Deliormanli, Izmir Institute of Technology, Chemical Engineering Department, Gülbahçe Köyü, 35430, Urla, Izmir Turkey (e-mail: aylindeliormanli@iyte.edu.tr)

(C) 2005 Wiley Periodicals, Inc. the second group is based on the sharp indenter such as Vickers and Knoop indentation; indentation strength and surface crack in flexure.$^{6-10}$ In most of the studies reported in the literature, the fracture toughness of dental materials was determined using the indentation fracture (IF) technique. ${ }^{6}$ This method requires small specimen sizes and is simple to apply. Therefore, the technique is very convenient when the material to be tested is very small in size. Microindentation tests are also able to measure some important mechanical properties including hardness, elastic modulus, creep, and the fracture toughness. To calculate the fracture toughness with the use of data obtained from the indentation test is however problematic. ${ }^{11,12}$ The results may contain high dispersions resulting from the difficulties inherited with the accurate measurement of crack length and subcritical slow crack growth. ${ }^{1}$ Large discrepancies between the fracture toughness values obtained from single edge notched beam (SENB) and the IF techniques were previously reported by Hornberger and Marquis. ${ }^{13}$ It is also noted that few researchers applied the indentation strength technique in dentistry. ${ }^{6}$ On the other hand, both indentation crack length (fracture) and indentation strength methods can be successfully used to measure fracture toughness values of ceramic materials only at ambient temperatures at which neither significant slow crack growth nor R-curve behavior observed. 
When more than one option is available in a laboratory, the choice of appropriate procedure is important to maximize the quantity and accuracy of the results. The factors which may effect the decision-making on the selection of technique include the form, size, and the thickness of sample, the hardness and ductility of the material to be tested, sample homogeneity, desired statistical confidence limits of the results, and the reasons for which the microindentation hardness data needed, for example, for abrasion resistance, a scratch technique may be more useful than quasistatic technique. ${ }^{14,15}$

The aim of the present work was to measure the fracture toughness of the human teeth enamel using the microindentation technique and to compare the calculated results of the equations developed for Palmqvist and radial-median cracks. The indentation tests were also conducted on dentine and on a sintered alumina sample. The indentation and indentation induced crack behavior of enamel and hardness values of dentine and alumina were analyzed. The fracture toughness formulations appropriate for the human enamel were then determined based on the comparison made between the results of present and previous studies.

\section{THEORY}

\section{Vickers Microhardness}

The Vickers microhardness test uses a square-base diamond pyramid as the indenter. The angle between opposite faces of the pyramid is $136^{\circ}$ (Figure 1). Because of the shape of the indenter, the test is often called the diamond-pyramid hardness test. The diamond-pyramid hardness number (DPH) or Vickers hardness number (VHN) is defined as the load divided by the surface area of the indentation. In practice, the indentation area is calculated from the microscopic measurements of the lengths of the diagonals of the impression. ${ }^{14,16,17,18}$ The Vickers hardness number is computed using the following equation:

$$
\mathrm{VHN}=\frac{2 P \sin \left(\frac{\theta}{2}\right)}{L^{2}}=1.854 P / L^{2}
$$

Where $P$ is the applied load $(\mathrm{kg}), L$ is the average length of the diagonal $(\mathrm{mm})$, and $\theta$ is the angle between opposite faces of diamond $\left(136^{\circ}\right)$. Most of the microhardness tests employ a small symmetrical indenter that penetrates into the surface of the material at a given load.

A considerable number of international standards are available for conducting microindentation hardness testing. Most of them are found in three sources: DIN (German), ISO, and ASTM. The DIN standards for Vickers and Knoop testing are numbered as 50133 and 52333, respectively. The ISO lists three Vickers Hardness Test related standards: R81, R 192, and R399. ${ }^{14}$

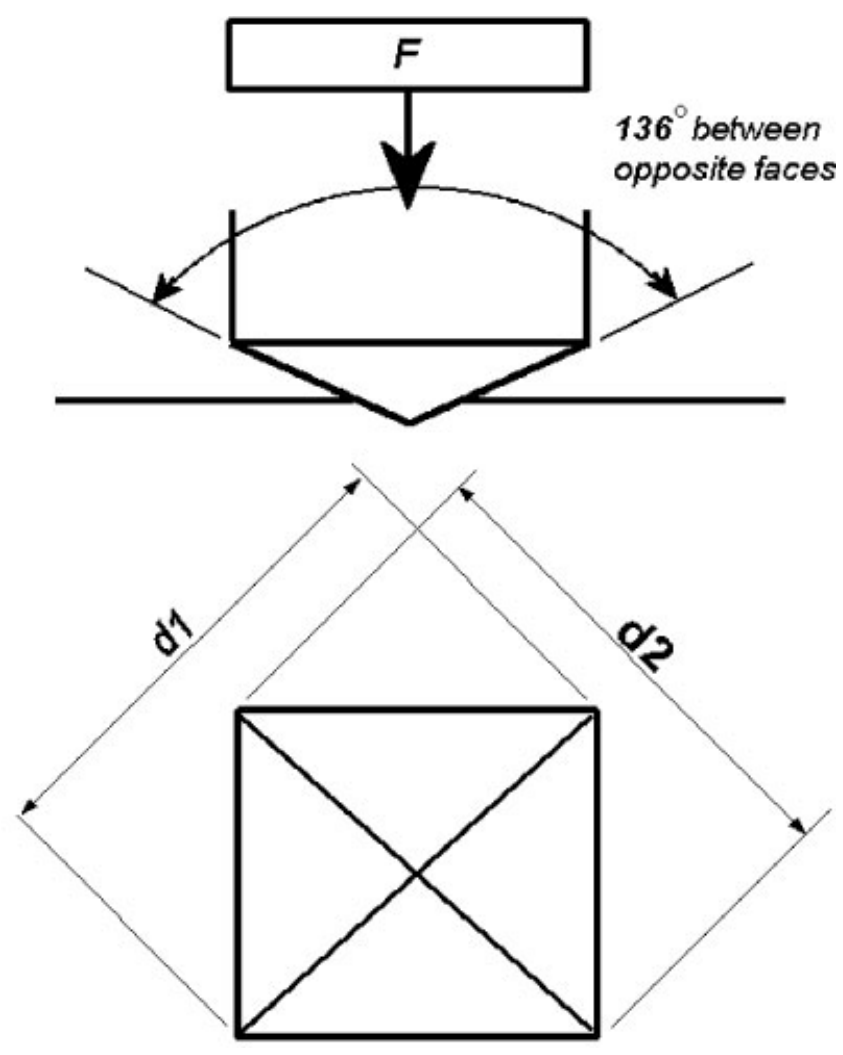

Figure 1. Vickers pyramid diamond indenter indentation. ${ }^{19}$

\section{Fracture Toughness}

If the load applied to a sample containing crack is too high, the crack may suddenly grow causing the sample failure in a brittle manner without inelastic deformation. From the theory of the fracture mechanics, a quantity called the stress intensity factor, $K$, characterizes the severity of the crack as affected by crack size, stress, and geometry. In linear-elastic fracture mechanics, the material is assumed to behave linearly elastic (Hooke's Law). A given material can resist a crack without brittle fracture as long as the value of $K$ is below a critical value $K_{\mathrm{C}}$, which is called the fracture toughness. Fracture toughness values can vary greatly for different groups of materials and are affected primarily by the temperature and loading rate and secondarily by the thickness of the sample. , $^{57,18,28}$

The fracture of brittle materials is usually controlled by the fracture toughness mode $I$. A simple dimensional analysis of a body containing a crack of length 2a subjected to an applied stress shows that the stress intensity factor at the crack and fracture toughness mode $I\left(K_{\mathrm{IC}}\right)$ is:

$$
K_{\mathrm{IC}}=\sigma Y \sqrt{a}
$$

where $Y$ is a dimensionless constant, which depends on the loading geometry and the crack configuration. The fracture toughness of brittle materials is usually considered as a material parameter because the plane strain conditions occur over the entire range of stress intensity factor. ${ }^{18}$ Under certain 
TABLE I. Equations Used in the Evaluation of Fracture Toughness. ${ }^{5,14,20,29,31,32,33}$

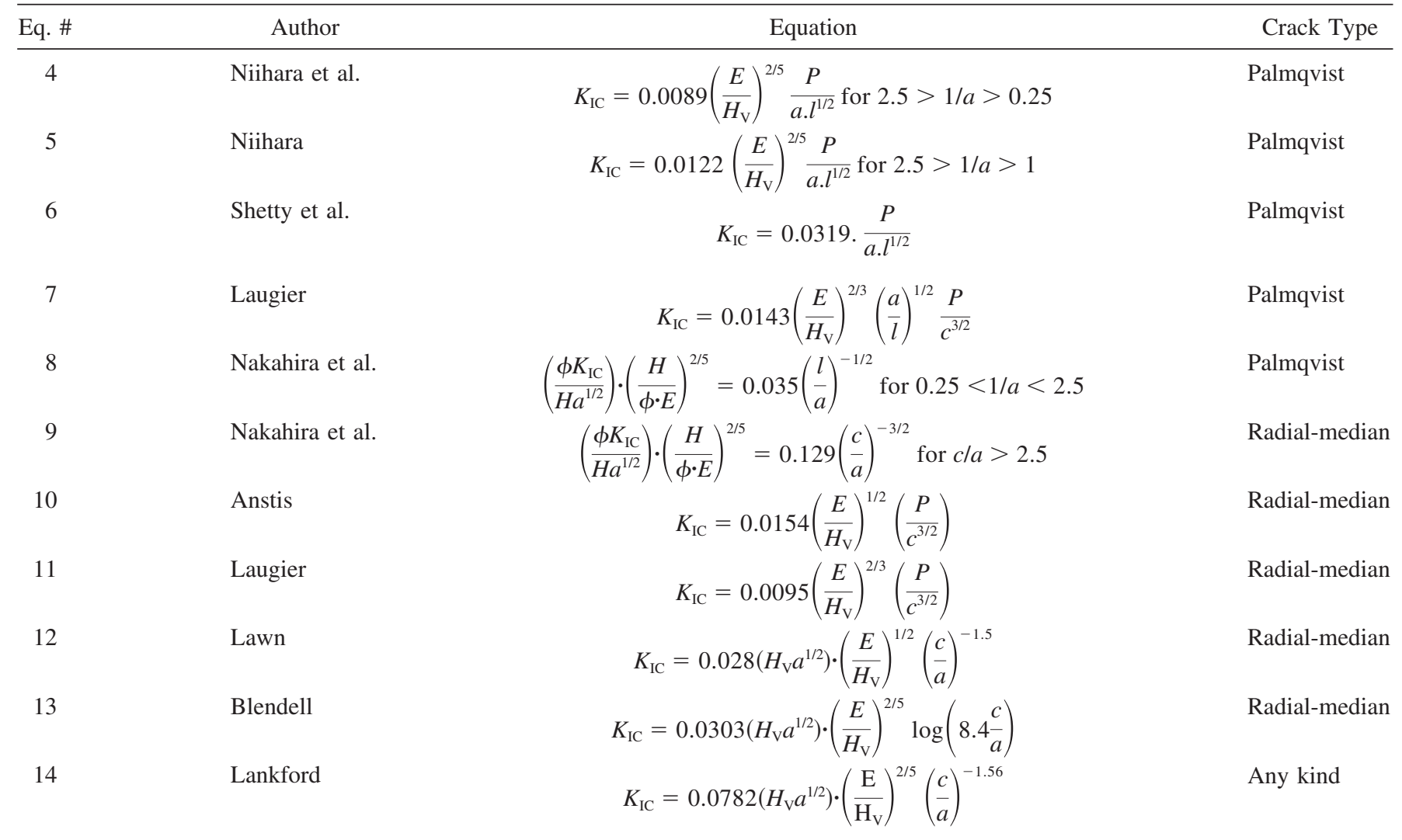

$H_{\mathrm{V}}$ and $H$, Vickers hardness number in (GPa); $P$, load during Vickers test; $2 a$,-indentation mark diagonal; and $l=c-a$ where $c$ is total crack length from center of hardness mark, $E$, the Young's modulus in $(\mathrm{GPa}) ; l$, the Palmqvist crack length from the center of the indent to the crack in $(m)$; $a$, is the indenter radius in $(m)$; $\Phi$ is a geometric constant (Zhao et al., 1993).

conditions, stable crack extension or slow crack growth can occur at stress intensities less than the $K_{\mathrm{IC}}$. Under such conditions, $K_{\mathrm{I}}$ depends on the crack growth rate (crack velocity) and hence the characteristics of the system. ${ }^{5}$

\section{Indentation Fracture}

In this technique, a Vickers indentation is implanted onto a flat surface and cracks developed at the corners of indentation are proportional to the toughness of the material. From the measurements of the lengths of the crack formed around the indentation, the fracture toughness is calculated. Marshall and colleagues investigated residual stresses and the influence of the geometric shape in elastic-plastic indentation. However, so far no exact solution of the indentation stress field has been achieved. Anstis and colleagues ${ }^{29}$ employed a simplified twodimensional fracture mechanics analysis and obtained the following equation ${ }^{5,6}$ :

$$
K_{\mathrm{IC}}=\xi\left(\frac{E}{H_{\mathrm{V}}}\right)^{1 / 2}\left(\frac{P}{c^{3 / 2}}\right)
$$

where $c$ is the crack length from the center of the indent to the crack, $E$ is the elastic modulus $(\mathrm{GPa}), H_{\mathrm{V}}$ is the Vickers hardness, and $\zeta$ is a material independent, dimensionless calibration constant which characterizes the geometry of the deformation field (0.016). Zhao and colleagues ${ }^{9}$ investigated the fracture behavior of $\mathrm{Al}_{2} \mathrm{O}_{3}$ containing $5 \mathrm{vol} \%$, $0.15 \mu \mathrm{m}$ silicon carbide ( $\mathrm{SiC}$ ) particles using indentation technique. The value of $\zeta$ was taken 0.022 rather than 0.016 for compensating the difference between the equilibrium crack lengths and thus toughness between systems in moist air and inert conditions. An empirical method for determining $K_{\mathrm{IC}}$ from Vickers microhardness testing was however first developed by Palmqvist. ${ }^{20,28}$ The Palmqvist crack model equation can also be used to compute fracture toughness when only shallow cracks form. Several authors have used the same technique to develop a number of relations between $K_{\mathrm{IC}}$, load, indentation diagonal length, crack length from the center of the indentation, Young's modulus, and Vickers hardness number of a material. The numerous indentation fracture models reported in the literature divided into two different groups. In the first group, it is assumed that the cracks that form from the Vickers indentation marks are well developed radial-median or halfpenny-shaped cracks. The other group assumed radial Palmqvist cracks are formed. ${ }^{6,20}$ The equations commonly used to calculate $K_{\mathrm{IC}}$ for Palmqvist and radial-median cracks are tabulated in Table I. 


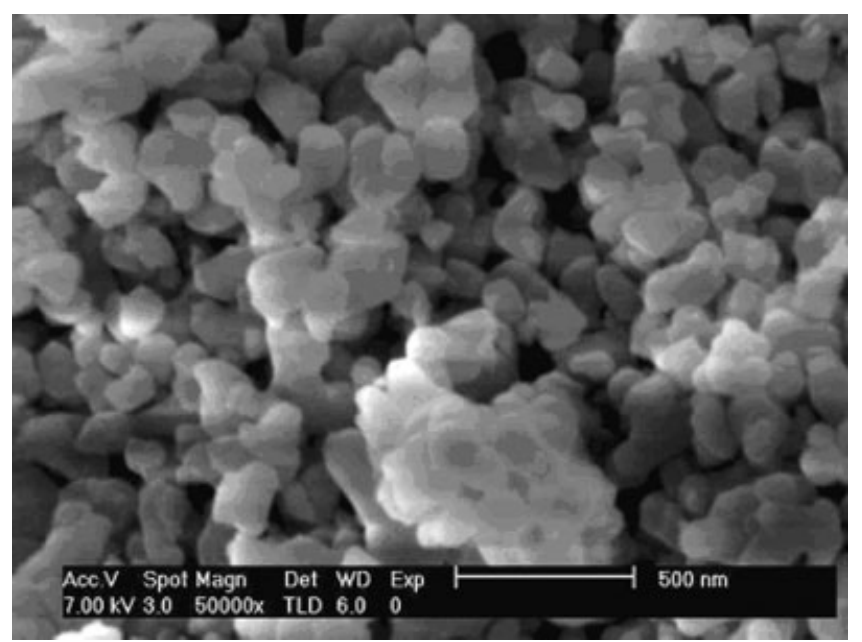

Figure 2. SEM micrograph of AKP-50 alumina powder.

\section{EXPERIMENTAL}

\section{Materials}

The sintered alumina ceramic material was manufactured using $99.99 \%$, pure alpha alumina powder (AKP 50, Sumitomo, Osaka, Japan) and contained trace elements of $140 \mathrm{ppm}$ $\mathrm{Si}, 7 \mathrm{ppm} \mathrm{Na}, 20 \mathrm{ppm} \mathrm{Mg},<1 \mathrm{ppm} \mathrm{Cu}$, and 9 ppm Fe. The main properties of the powder are as follows: mean particle size of $0.2 \mu \mathrm{m}$, BET surface area of $12.3 \mathrm{~m}^{2} \mathrm{~g}^{-1}$, tapped bulk density of $1.5 \mathrm{~g} \mathrm{~cm}^{-3}$, and loose bulk density of $1.1 \mathrm{~g} \mathrm{~cm}^{-3}$. Figure 2 shows a SEM micrograph of AKP-50 alumina powder. The second material tested was the human teeth, extracted human molars, which were supplied by the Faculty of Dentistry of Ege University (Turkey).

\section{Sample Preparation}

Cube-shaped ceramic specimens were produced via slip casting technique. Polyacrylic acid (Aldrich Chemicals, MW of $2000 \mathrm{~g} / \mathrm{mol}$ ) was used as dispersant for the slurry preparation. Sintering of slip cast specimens was performed at $1450^{\circ} \mathrm{C}$ inside a Carbolite RHF 1600 type high temperature furnace in air atmosphere.

The received molar teeth were disinfected using $1 \%$ solution of hydrogen peroxide (Milton's Solution) at $4^{\circ} \mathrm{C}$ for $48 \mathrm{~h}$ and then stored in distilled water until they were tested. Samples were cut from the central portion of the crown using a slow speed diamond saw such that the cut was perpendicular to the buccalingual division line. Then all of the samples were prepared for microhardness testing using the following procedure:

1. Samples were mounted inside acrylic resin.

2. Samples were grinded using a Metaserv 2000 Grinder (Buehler) at a speed $350 \mathrm{rev} \mathrm{min}^{-1}$ with $\mathrm{SiC}$ grinding papers of 600 through 1000 grit size.

3. Samples were polished with $\mathrm{SiC}$ diamond solutions with grit sizes 6 down to $1 \mu \mathrm{m}$.
It is important to note that in order to obtain representative microindentation hardness numbers, especially at low range of test loads, no effects of sample grinding or polishing damage can be tolerated. If the indenter loads are over about $0.98 \mathrm{~N}$ careful mechanical metallographic procedures usually suffice. ${ }^{17}$ In order to observe the grain boundaries and grain sizes of the ceramic specimen, chemical etching was applied using $98 \% \mathrm{H}_{2} \mathrm{SO}_{4}$ at $100^{\circ} \mathrm{C}$ for $60 \mathrm{~min}$.

\section{Hardness Testing}

Hardness measurements were conducted using a Time Instrument HV 1000 Vickers Microhardness tester. No etching was applied to the polished surfaces of the samples as it may create surface irregularities affecting the indentation and the visibility of the indentation under microscope. Indentations were conducted on the polished faces of the specimens using a Vickers diamond pyramid at various peak contact loads. Microhardness tests on alumina were conducted at $9.8 \mathrm{~N}$, $4.9 N, 2.94 N, 1.96 N$, and $0.98 N$ indentation loads for $15 \mathrm{~s}$. For each load cycle three different measurements were carried out and the results were averaged. The Vickers microhardness measurements of the teeth were made on two different sections of the specimen. In dentine, only $9.8 \mathrm{~N}$ peak load was applied while in enamel section indentations were performed at $9.8 \mathrm{~N}, 4.9 \mathrm{~N}$, and $2.94 \mathrm{~N}$ for $10 \mathrm{~s}$. In total, five teeth samples were prepared and tested and three measurements at 9.8, 4.9, and $2.94 \mathrm{~N}$ were carried out for each sample. Microscopic observations of the cracks were performed using an Olympus B 201 optical microscope.

\section{RESULTS AND DISCUSSION}

\section{Alumina}

Figure 3 shows the optical micrograph of the sintered alumina specimen after chemical etching. The grain size of the specimen was measured 1 to $2 \mu \mathrm{m}$ from the micrograph. The microhardness tests results of alumina are listed in Table II.

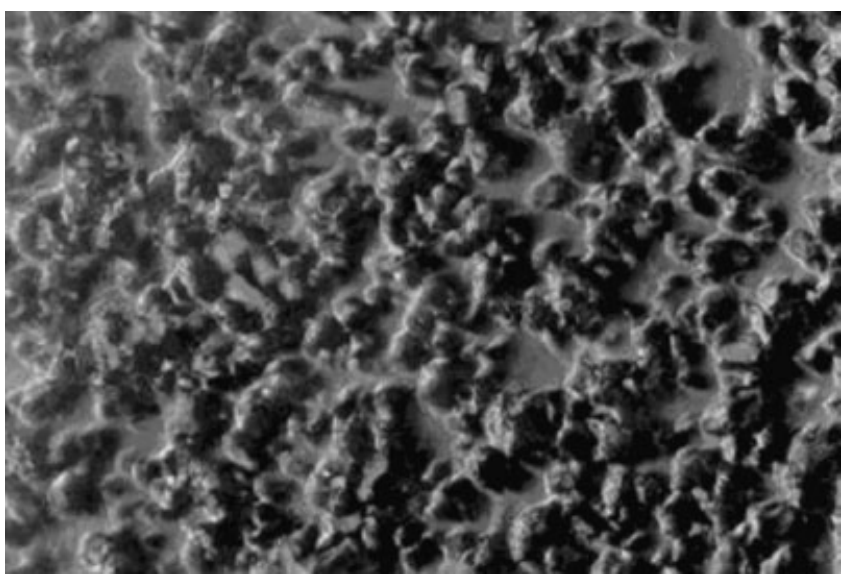

Figure 3. Optical micrograph of sintered alumina grains $(100 \times)$ : etched surface. 
TABLE II. Vickers Microhardness Test Results of the Alumina

\begin{tabular}{lcccc}
\hline Indenter load & $9.8 N$ & $4.9 N$ & $2.94 N$ & $1.96 N$ \\
\hline Indentation time $(\mathrm{s})$ & 15 & 15 & 15 & 15 \\
Diagonal $D_{1}(\mu \mathrm{m})$ & 34.292 & 25.54 & 20.34 & 17.12 \\
Diagonal $D_{2}(\mu \mathrm{m})$ & 34.292 & 25.54 & 20.34 & 17.12 \\
Vickers hardness $H_{\mathrm{V}}{ }^{*}$ & 1522 & 1468 & 1345 & 13.31 \\
$H_{\mathrm{V}}(\mathrm{GPa})$ & 14.92 & 14.39 & 13.18 & 13.31 \\
\hline
\end{tabular}

* These values are the average of three different indentation measurements.

Vickers microhardness value of sintered alumina $(98.8 \%$ theoretical density) is $14.92 \mathrm{GPa}$ at $9.8 \mathrm{~N}$ indentation load and decreases as the indenter load decreases. Kisly and Gritsenko ${ }^{21}$ reported that the hardness of oxide ceramics ranges between 14.5 and $21 \mathrm{GPa}$ and measured the microhardness of $\mathrm{Al}_{2} \mathrm{O}_{3}$ as $20 \mathrm{GPa}$. In a study, Zhao and colleagues ${ }^{9}$ found the hardness of $99.3 \%$ density sintered alumina $20.3 \mathrm{GPa}$ at $1.24 \mathrm{~N}$ indentation load. However, Khan and colleagues ${ }^{22}$ reported a lower microhardness value, $17.3 \mathrm{GPa}$, and a fracture toughness of $3.26 \mathrm{MPa} \cdot \mathrm{m}^{1 / 2}$. The study carried out by $\mathrm{Krell}^{23}$ indicated similar results for the fracture toughness of the sintered alumina. The alumina bodies with relative densities of $99.2 \%$ were produced by aqueous powder processing and pressureless sintering in air and had $K_{\mathrm{IC}}$ values ranging between of 3.5 and $4 \mathrm{MPa} \cdot \mathrm{m}^{1 / 2}{ }^{23}$ In recent studies, the hardness values were reported in wider load scale and it was shown that the load range between 2 and $200 N$ can give more accurate results for hardness value of the specimen, especially for the calculation of the fracture toughness by indentation fracture method. ${ }^{9}$ The relatively low microhardness values of the studied alumina as compared with the reported values are most likely due to relatively lower density. Within the applied load range no cracks formed in the samples; therefore, the fracture toughness could not be calculated.

The enamel is the hardest substance in the human body and consists of 92 to 96 vol \% of relatively large hydroxyapatite crystals, which are mostly contained in the basic structural unit of the enamel called rods or prisms, and an

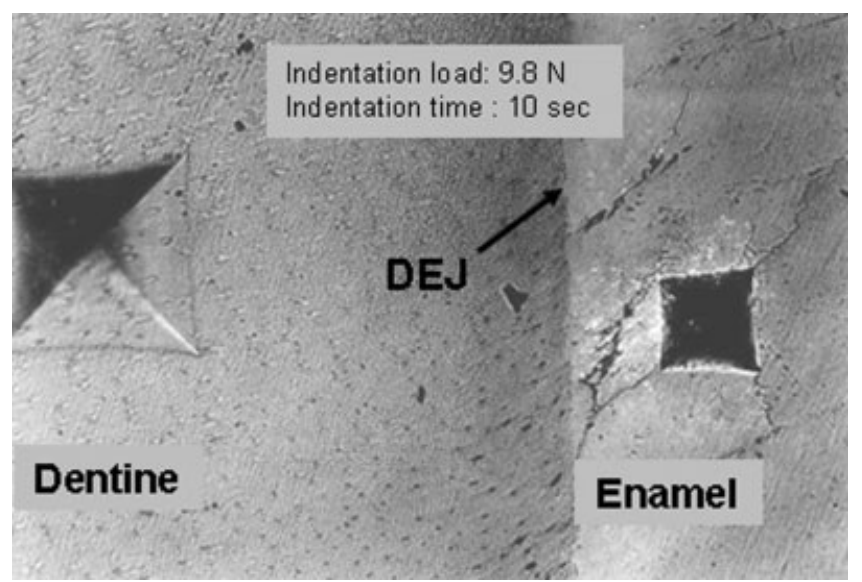

Figure 4. Optical micrograph of Vickers indentation in enamel and dentine $(9.8 \mathrm{~N})$ showing enamel cracks arrested by the DEJ. organic phase, which separates the rods. On the other hand, human dentine is a mineralized tissue whose distribution of organic matrix and minerals is similar to that of regular compact bone. It is a hydrated composite material composed of nanocrystalline carbonated apatite mineral (45 vol \%), type-I collagen fibrils (30 vol \%), and fluid (25 vol \%). Dental

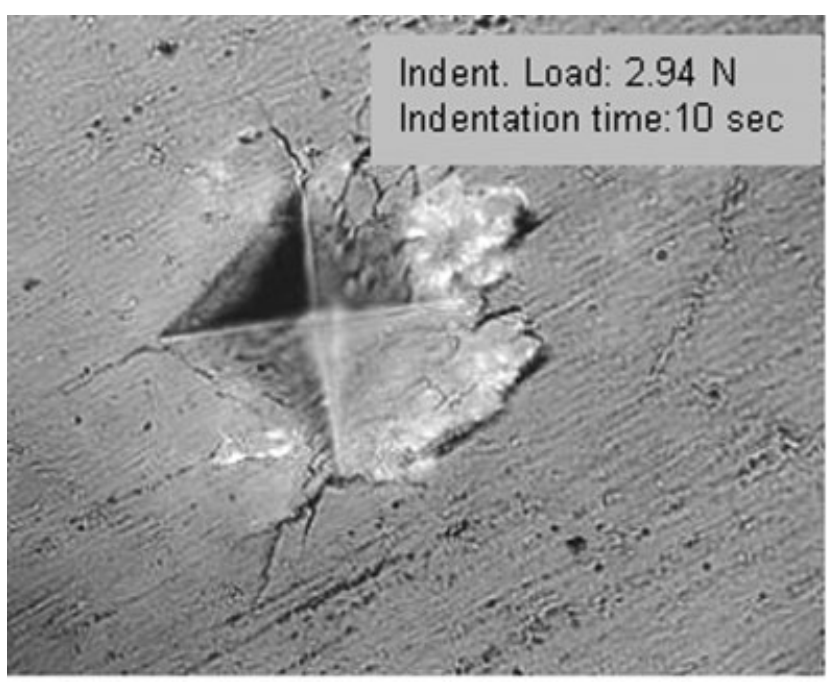

(a)

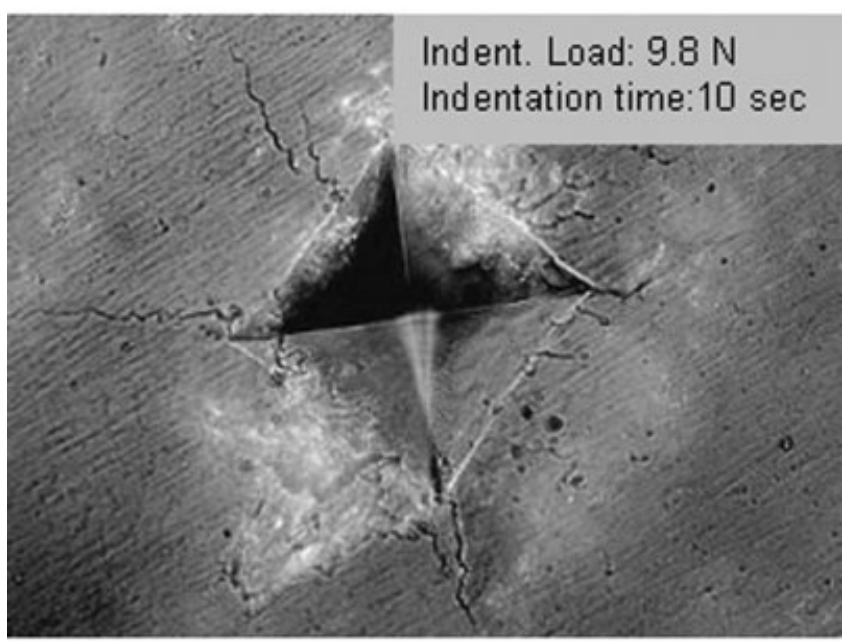

(b)

Figure 5. Indentation and cracks in enamel under (a) 2.94 and (b) $9.8 \mathrm{~N}$ peak loads. 
TABLE III. Vickers Microhardness Test Results (Maximum-Minimum) of the Teeth

\begin{tabular}{lcccc}
\hline Indenter load & $9.8 N$ dentine & $9.8 N$ enamel & $4.9 N$ enamel & $2.94 N$ enamel \\
\hline Indentation time $(\mathrm{s})$ & 10 & 10 & 10 & 10 \\
Diagonal $D_{1}(\mu \mathrm{m})$ & $176.62(168.9-181.1)$ & $75.95(72.5-79.0)$ & $54.58(53.8-56.0)$ & $44.9(42.1-47.8)$ \\
Diagonal $D_{2}(\mu \mathrm{m})$ & $175.98(168.5-179.6)$ & $78.13(74.6-82.1)$ & $57.22(54.6-58.4)$ & $44.17(41.8-49.0)$ \\
Hardness $H_{\mathrm{V}}$ & $59.8(56.95-65.15)$ & $311.8(290-320)$ & $290.2(282-311)$ & $283.1(265-302)$ \\
\hline
\end{tabular}

tubules radiate from the pulp cavity toward the perishering and penetrate every part of the dentine. ${ }^{24}$ Between enamel and dentine there is a biological interface which dissipate stresses inhibiting crack propagation. ${ }^{34}$ Teeth must work under the applied stress of about $20 \mathrm{MPa}$ some times 3000 times per day without fatigue failures and only with moderate wear. ${ }^{25}$ The elastic modulus of the teeth in compression varies between 9 and $84 \mathrm{GPa}$ for the enamel and 11 and 17 GPa for the dentine. The elastic modulus of dentine ranges between 11 and $19 \mathrm{GPa}$ in tension. ${ }^{21,25,26}$

In the present study microhardness tests for the fracture toughness determination of the enamel were performed at a distance about $200 \mu \mathrm{m}$ from the occlusal surface in the lingual section and indentor loading was primarily perpendicular to the rod direction. Microhardness tests near the dentine-enamel junction (DEJ) and in the dentine section were also conducted. Figure 4 shows microhardness indentions near the DEJ region in the enamel and dentine at the same peak load. Indentation cracks seen at the corners of the indentation in the enamel section proved the brittle nature of enamel, while no cracks seen in dentine confirmed its relatively higher ductility. When a brittle material is plastically deformed by a pyramid indenter, fracture usually occurs at the corners where the stress field is at maximum. ${ }^{28}$ It should also be noted in the same figure that a long crack running from one of the corners of the indentation in the enamel section is arrested by the DEJ. Figures 5(a) and (b) show the indentations and associated cracks in the enamel section at 2.94 and $9.8 \mathrm{~N}$ peak loads, respectively. It is noted that at increasing peak load values the length of the cracks formed at the corners of indentation increases. In addition to these long cracks, small side cracks are also seen in Figures 5(a) and (b). In a previous study ${ }^{1}$ it was found that the indentation cracks in the axial section were longer in the direction parallel to the enamel rods than perpendicular. These longer cracks normal to occlusal surface were radial-median cracks, spanning under the indentation area. The orientation of the enamel rods also affects the fracture toughness values.

Tables III and IV summarizes the results of microhardness

TABLE IV. Crack Length Values of the Teeth Enamel after Microindentation

\begin{tabular}{lccc}
\hline Indentor load & $9.8 N$ & $4.9 N$ & $2.94 N$ \\
\hline Crack length, $l(\mu \mathrm{m})$ & 38.1 & 24.8 & 15.1 \\
Indenter radius, $a(\mu \mathrm{m})$ & 38.0 & 25.6 & 14.9 \\
Median crack length, $C(\mu \mathrm{m})$ & 76.1 & 50.4 & 30.0 \\
\hline
\end{tabular}

tests conducted in dentine and enamel region. The hardness $\left(H_{\mathrm{V}}\right)$ values are 59.8 and 311.8 at $9.8 \mathrm{~N}$ peak load for dentine and enamel, respectively. The $H_{\mathrm{V}}$ value of enamel increases from 283.1 to 311.8 with increasing peak load from 2.94 to $9.8 N$. A previous study ${ }^{30}$ conducted using a nanoindenter in the axial lingual section has shown that the hardness values ranged between 3 and $6 \mathrm{GPa}$ and higher hardness values were measured near to the occlusal surface. Therefore the measured hardness values show good agreement as the indentation tests were performed near to the occlusal surface. In the study carried by $\mathrm{Xu}$ and colleagues ${ }^{1}$ the hardness value was reported to be $3.14 \mathrm{GPa}$ for the axial section. The differences between the measured hardness values of different studies may be attributed to the complex chemical and physical structure of teeth, which varies with the location along axial section depending on the rod orientation and chemical composition.

Fracture Toughness Calculation. The model equations used for the evaluation of fracture toughness are listed in Table I. In this table, equations numbered from 4 to 8 are for Palmqvist type cracks (see Figure 6), equations from 9 to 13 for radial-median type cracks, and Equation 14 for both types of cracks. Using these equations the fracture toughness values of enamel in axial direction were calculated and the results are shown in Figure 7. In calculations, the elastic modulus for enamel was taken $50 \mathrm{GPa}^{25}$ It is shown in Figure 7 that the

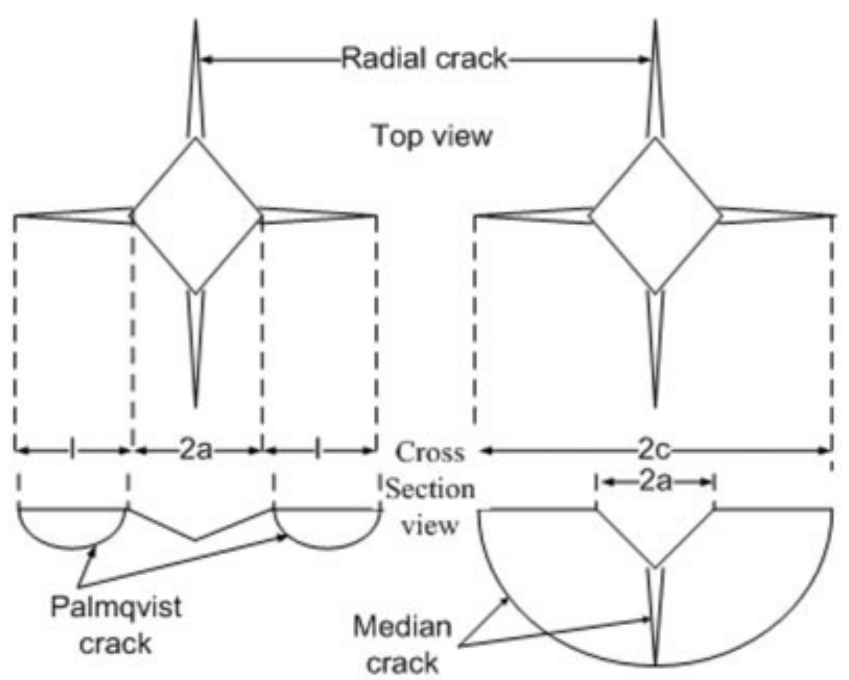

Figure 6. Palmqvist and median crack geometries around a Vickers indentation. 
equations of Palmqvist crack predict higher values of fracture toughness values than those of radial-median cracks. Rizkalla and Jones ${ }^{27}$ have reported the fracture toughness values of natural tooth enamel in the range of 0.7 to 1.37 and natural tooth dentine as $3.08 \mathrm{MPa}^{1 / 2}$. Most of the equations listed in Table I result in fracture toughness values within this reported range. However, $\mathrm{Xu}$ and colleagues ${ }^{1}$ reported fracture toughness values of $0.84,0.58$, and $1.55 \mathrm{MPa}^{1 / 2}$ for enamel occlusal region and the axial regions of rods parallel and normal to the occlusal region, respectively. Hassan and co-workers ${ }^{28}$ reported toughness values in the axial direction ranging about $0.7 \mathrm{MPa} . \mathrm{m}^{1 / 2}$. The results obtained in the present study using Equations 10, 11 and 12 of radial median cracks show therefore good agreements with the previous studies of $\mathrm{Xu}$ and Hassan (the rectangular area in Figure 7). Equations developed for Palmqvist cracks should be used carefully because they resulted in relatively higher fracture toughness values.

The indentation energy is also seen to partially dissipate by the small cracks formed at sides of indentations (Figure 5). These cracks naturally reduce the measured fracture toughness in an extent depending on the type (shallow or deep) and size. Therefore their effects should be further analyzed microscopically. The results also show that toughness evaluation by indentation method strongly depends on the crack type and length; therefore, crack profile should be observed carefully to select the suitable equation. In addition the complex chemical and physical nature of the teeth requires the specification of test region.

\section{CONCLUSION}

In this study, Vickers microhardness measurements of two different materials were performed. The fracture toughness of human teeth enamel was calculated using the equations de-

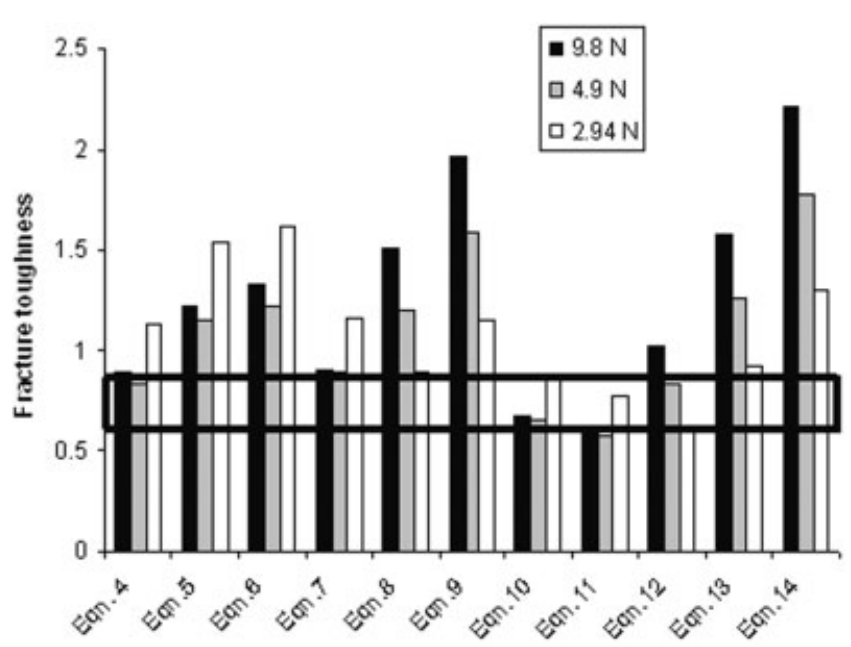

Figure 7. Fracture toughness values $\left(\mathrm{MPa}^{\mathrm{m}} \mathrm{m}^{1 / 2}\right)$ of equations listed in Table I (the rectangle shows the range of the previously measured fracture toughness data of $\mathrm{Xu}$ and colleagues ${ }^{1}$ and Hassan and colleagues $^{28}$ in the axial direction). veloped for Palmqvist and radial-median cracks. Compared to the previous results of fracture toughness determination in the axial direction of enamel, the present study showed good agreements using the equations of Anstis, Laugier, and Lawn. Results indicated that indentation technique was also adequate for the microhardness measurements of the dental ceramic samples and is suitable in particular for the dental field. However the evaluation of the fracture toughness strongly depended on the nature of the cracks and also on the location of the indentation. Therefore a careful observation is necessary for the crack type and microstructral orientation of the teeth to select the suitable equation for the fracture toughness calculation.

\section{REFERENCES}

1. Xu HHK, Smith DT, Jahanmir S, Romberg E, Kelly JR, Thompson VP, Rekow ED. Indentation damage and mechanical properties of human enamel and dentin. J Dent Res 1998;77: 472-480.

2. Morrone AA, Nutt SR, Suresh S. Fracture toughness and fatigue crack growth behavior of an $\mathrm{Al}_{2} \mathrm{O}_{3}-\mathrm{SiC}$ composite. J Mater Sci 1988;23:3206-3213.

3. Wang L, Wixom MR, Thompson LT. Structural and mechanical properties of $\mathrm{TiB}_{2}$ and $\mathrm{TiC}$ prepared by self-propagating hightemperature synthesis/dynamic compaction. J Mater Sci 1994; 29:534-543.

4. Degnan CC, Kennedy AR, Shipway PH. Fracture toughness measurements of powder metallurgical (P/M) green compacts: a novel method of sample preparation. J Mater Sci 2004;39:26052607.

5. Amin KA. Ceramics and glasses. Engineered materials handbook: Hardness, toughness and wear. Metals Park, OH: ASM International; 1987. p 599.

6. Scherrer SS, Denry IL, Wiskott HWA. Comparison of three fracture toughness testing techniques using a dental glass and a dental ceramic. Dent Mater 1998;14:246-255.

7. Niihara K, Unal N, Nakahira A. Mechanical properties of (Y-TZP) alumina-silicon carbide nanocomposites and the phase stability of Y-TZP particles in it. J Mater Sci 1994; 29:164-168.

8. Wang R. Fracture toughness and interfacial design of a biological fiber-matrix ceramic composite in sea urchin teeth. J Am Ceram Soc 1998;81:1037-1040.

9. Zhao J, Stearns LC, Harmer MP, Chan HM, Miller GA, Cook RF. Mechanical behavior of alumina-silicon carbide nanocomposites. J Am Ceram Soc 1993;76:503-510.

10. Wang L, D’alpino PHP, Lopes LG, Pereira JC. Mechanical properties of dental restorative materials: relative contribution of laboratory tests. J Appl Oral Sci 2003;11:162-167.

11. Fischer H, Marx R. Fracture toughness of dental ceramics: comparison of bending and indentation method. Dent Mater 2002;18:12-19.

12. Mahoney E, Holt A, Swain M, Kilpatrick N. The hardness and modulus of elasticity of primary molar teeth: an ultra-microindentation study. J Dentistry 2000;28:589-594.

13. Hornberger H, Marquis PM. Mechanical properties and microstructure of In- Ceram, a ceramic-glass composite for dental crowns. Glastech Ber Glass Sci Technol 1995;68:188-194.

14. Blau JP. Methods and applications of microindentation hardness testing, applied metallography. New York: Van Nostrand Reinhold; 1986. p 123-138. 
15. Subhash G, Ravichandran G. Mechanical behavior of hot pressed aluminum nitride under uniaxial compression. J Mater Sci 1998;33:1933-1939.

16. ASTM Designation E384-89. Standard test method for microhardness of materials. In: ASTM Standards. Philadephia: American Society for Testing and Materials; 1997.

17. Dieter EG. Mechanical metallurgy, metric editions. London: McGraw-Hill; 1988.

18. Dowling EN. Mechanical behavior of materials, engineering methods for deformation fracture and fatigue. Englewood Cliffs, NJ: Prentice-Hall; 1993.

19. Gordon England Independent Metallurgist and Consultant to Thermal Spray Coating Industry. http://www.gordonengland. co.uk.

20. Milekhine V, Onsoien MI, Solberg JK, Skaland T. Mechanical properties of $\mathrm{FeSi}(\epsilon), \mathrm{FeSi}_{2}\left(\zeta_{\alpha}\right)$ and $\mathrm{Mg}_{2} \mathrm{Si}$. Intermetallics 2002;10:743-750.

21. Kisly PS, Gritsenko EI. Superhard materials for cutting operations, ceramics today-tomorrow's ceramics: proceedings of the 7th International Meeting on Modern Ceramics Technologies (7th CIMTEC - World Ceramics Congress). Amsterdam: Elsevier Science Publishers; 1991.

22. Khan A, Chan HM, Harmer MP, Cook RF. Toughness-curve behavior of an alumina mullite composite. J Am Ceram Soc 1998;81:2613-223.

23. Krell A. Fracture origin and strength in advanced pressurelesssintered alumina. J Am Ceram Soc 1998;81:1900-1907.

24. Imbeni V, Nalla RK, Bosi C, Kinney JH, Ritchie RO. In vitro fracture toughness of human dentine. J Biomed Mater Res 2003;66A:1-9.
25. Suchanek W, Yoshimura M. Processing and properties of hydroxyapatite-based biomaterials for use as hard tissue replacement implants. J Mater Res 1998;13:94-117.

26. Cahn RW, Haasen P, Kramer EJ. Material science and technology: medical and dental materials. A compressive treatment. Germany: VCH; 1992. p 14.

27. Rizkalla AS, Jones DW. Indentation fracture toughness and dynamic elastic moduli for commercial feldspathic dental porcelain materials. Dent Mater 2004;20:198-206.

28. Hassan R, Caputo AA, Bunshah RF. Fracture toughness of human enamel. J Dent Res 1981;60:820-827.

29. Anstis GR, Chantikul P, Lawn BR, Marshall DB. A critical evaluation of indentation techniques for measuring fracture toughness: I. Direct crack measurements. J Am Ceram Soc 1981;64:533-538.

30. Cuy JL, Mann AB, Livi JK, Teaford MF, Weihs TP. Nanoindentation mapping of the mechanical properties of human molar tooth enamel. Arch Oral Biol 2002;47:281-291.

31. Clement J, Torres P, Gil FJ, Planell JA, Terradas R, Martinez S. Evaluation by Vickers indentation of fracture toughness of a phosphate biodegradable glass. J Mater Sci Mater Med 1999; 10:437-441.

32. Niihara K, Morena R, Hasselman DPH. Evaluation of KIC of brittle solids by the indentation method with the low crack to indent ratios. J Mater Sci Lett 1982;1:13-16.

33. Laugier MT. New formula for indentation toughness in ceramics. J Mater Sci Lett 1987;6:355.

34. Giannini M, Soares CJ, Carvalho RM. Ultimate tensile strength of tooth structures. Dent Mater 2004;20:322-329. 